\title{
Influence of socioeconomic factors on daily life activities and quality of life of Thai elderly
}

\author{
Ratana Somrongthong, ${ }^{1}$ Sunanta Wongchalee, ${ }^{1}$ Chandrika Ramakrishnan, ${ }^{1}$ \\ Donnapa Hongthong, ${ }^{2}$ Korravarn Yodmai, ${ }^{3}$ Nualnong Wongtongkam ${ }^{4}$ \\ ${ }^{1}$ College of Public Health Sciences, Chulalongkorn University, Bangkok; ${ }^{2}$ Boromarajonani College \\ of Nursing, Phayao; ${ }^{3}$ Faculty of Public Health, Mahidol University, Thailand; ${ }^{4}$ School of \\ Biomedical Sciences, Charles Sturt University, NSW, Australia
}

Significance for public health

Increasing numbers of ageing population raise a public health concern in Thai society due to the increasing demands of medical and health services regarding chronic diseases and disability. Unfortunately, few studies have mentioned socioeconomic factors on daily living activities and quality of life and none has taken place across regions in Thailand. Epidemiological population-based studies are necessary to identify social determinants and potential contributing factors that influence quality of life and disability which in turn, may utilise information shaping the policy through better support and care.

\footnotetext{
Abstract

Background: The increasing number of older people is a significant issue in Thailand, resulted in growing demands of health and social welfare services. The study aim was to explore the influence of socioeconomic factors on activities of daily living and quality of life of Thai seniors.

Design and methods: Using randomised cluster sampling, one province was sampled from each of the Central, North, Northeast and South regions, then one subdistrict sampled in each province, and a household survey used to identify the sample of 1678 seniors aged 60 years and over. The Mann-Whitney U-test and binary logistic regression were used to compare and determine the association of socioeconomic variables on quality of life and activities of daily living.

Results: The findings showed that sociodemographic and socioeconomic factors were significantly related to functional capacity of daily living. Education levels were strongly associated with daily life activities, with 3.55 adjusted ORs for respondents with secondary school education. Gender was important, with females comprising $61 \%$ of dependent respondents but only $47 \%$ of independent respondents. Seniors with low incomes were more likely to be anxious in the past, present and future and less likely to accept death in the late stage, with 1.40 Adjusted ORs $(95 \% \mathrm{CI}$ : 1.02-1.92), and 0.72 (95\% CI: 0.53-0.98), respectively. However, they were more likely to engage in social activities.

Conclusions: While socioeconomic factors strongly indicated the functional capacity to live independently, a good quality of life also required other factors leading to happiness and life satisfaction.
}

\section{Introduction}

The increasing numbers of older people raises public health concerns in developed and developing countries. Older people have a high risk of chronic diseases, disabilities and frailty. ${ }^{1,2}$ The Global Burden of Disease study from 187 countries points out that healthy life expectancy has increased less than total life expectancy, by 0.8 years from 1990 to 2010, or in other words, the world is faced with morbidity expansion. ${ }^{3}$ In Asia, the senior population is expected to increase by $314 \%$ from 2000 to 2050 , with approximately 857 million persons aged 60 years or over. ${ }^{4}$

Thailand is one country of Southeast Asia that has experienced rapid growth in the number of frail people because of a dramatic decline in fertility and mortality rates. ${ }^{5}$ Total fertility rate has dropped from over six births per woman in the mid-1960s to just over two births per woman in the period $2005-2010,{ }^{5}$ falling to a projected birth rate of under 1.5 per woman in $2015 .{ }^{6}$ Thailand is ranked $32^{\text {nd }}$ in the world for the increase in numbers of senior adults, according to the Bloomberg report. Since 1960s, the number of those aged 60 years or over in the population in Thailand has increased steadily to over 8 million in 2010, and it is projected to reach over 20 million by 2040 , or over $30 \%$ of total population. ${ }^{7}$ Thailand has experienced rapid changes in social and economic development, moving from a low-income to a middle-upper income country in recent decades. Poverty has declined dramatically over the last 30 years, from $67 \%$ in 1986 to $7.2 \%$ in 2015.8 Following these economic and social improvements, life expectancy at birth has increased by approximately 10 years in three decades. ${ }^{9}$

The increase in life expectancy has placed considerable demands on medical and health services because of the chronic diseases and disability that often accompany old age. ${ }^{1}$ The Thailand National Statistic Office has pointed out that one-third of older people experience chronic health conditions, including diabetes, hypertension, cardiovascular and cerebrovascular diseases. ${ }^{10}$ Numerous studies have indicated that lifetime poverty since childhood has a strongly negative impact on health outcomes later in life, particularly in late adulthood and old age, because of increased earlier onset of functional disability and chronic diseases regardless of race or ethnicity. ${ }^{11,12}$ The lifetime socioeconomic situation of senior persons in developing countries is generally lower than for those in wealthy countries, ${ }^{2}$ which may affect their quality of life and ability to live independently in old age. Quality of life is one key indicator for healthy life expectancy. ${ }^{13}$ It is a multidimensional evaluation of an individual's ability in relation to their physical, mental, and social assets and is able to convey the overall well-being of life as a whole. ${ }^{14}$ 
Socioeconomic status is a broad perspective involving a myriad of psychological and sociological mechanisms that include social support, emotional stress, environmental aspects and access to medical care. ${ }^{15}$ Education and income variables are the two most common measures of socioeconomic status. ${ }^{16}$ Its strong relationship with health and well-being has often been demonstrated, but there is limited evidence about the impact of socioeconomic factors on good health across older age groups. ${ }^{17}$ A national survey of people aged 50 years and over in Thailand over two decades ago revealed that incomes, household possessions and education were strongly associated with self-assessed health and functional disorders in both males and females. ${ }^{17}$ A Thai study carried out between 1994 and 2007 demonstrated that the proportion of respondents rating their health as good increased by $8 \%$ during the period, while significantly fewer rated their health as poor in 2007 compared with 1994, in both urban and rural areas. As expected, persons with high incomes in urban or rural locations displayed better health across the two time periods. ${ }^{18}$ When considering the relation of income to life satisfaction and happiness, findings indicated no significant association between high income and life satisfaction, but income was strongly linked to happiness in Thais. ${ }^{19}$ Even though life satisfaction and happiness may both reflect quality of life to some extent, they are different in conceptualisation. For instance, quality of life is perceived as a by-product of experiencing pleasantness while happiness referred to an overall quality of one's life, similar to life satisfaction. ${ }^{20}$

Measures of disability are useful for indicating whether persons are able to live independently, and to show the need for social care services. ${ }^{21}$ There is some empirical evidence of the impact of socioeconomic aspects on the ability to perform daily living activities (ADL). Zhang et al. (1998) showed that age, gender, and chronic disease affected ADL in a Chinese population. ${ }^{22}$ A study of healthy life expectancy related to ADL in eight Asian nations has shown that disability-free life expectancy in frail persons decreased gradually as age increased. ${ }^{23}$ Similarly, national health surveys of elders in Thailand in 2002 and 2007 reported that mobility dependence increased with age in both genders, while mobility dependence for women increased in all age groups between 2002 and 2007, but decreased in men. ${ }^{2}$ When considering the influence of socioeconomic status on daily living, a Chinese study demonstrated positive associations between socioeconomic characteristics, particularly age, economic security and health, and ADL. ${ }^{24}$ However, there are debates about the extent of generalisability of findings between counties, because even those that appear to have similar ethnic backgrounds may have distinctive geographic, cultural and lifestyle behaviours.

There have been a few studies of frail peoples' health in Thailand to identify effects of socioeconomic factors on daily living activities but these have not investigated quality of life, nor were data collected across different regions. The study aimed to assess socioeconomic factors that may predict the quality of life and disability among seniors in Thailand.

\section{Ethical statement}

The study was approved by the Ethical Review Committee for Research Involving Human Research Subjects, Health Science Group, Chulalongkorn University, Thailand.

\section{Materials and Methods}

The study was a community-based cross-sectional study using randomised cluster sampling in 2012. Four provinces were sam- pled, one from each of the four regional areas in Thailand. These were Saraburi (Central), Payao (North), Khon-Khaen (Northeast), and Trang (South). The number of people aged 60 years or over accounted for almost $13 \%$ of total population in Saraburi $(162,025)$ and Trang $(150,100)$ provinces, while senior adults in Payao $(98,752)$ and Khon Khaen $(197,490)$ provinces comprised approximately $15 \%$ of total population. ${ }^{25}$ One subdistrict in each province was chosen, based on high population density and with mixed rural and urban characteristics. A door-to-door survey was conducted in target locations, and one person aged 60 years or over was selected from each household. Persons with cognitive impairment were excluded. The total sample was 1678 persons: 450 in Sarburi, 400 in Payao, 428 in Khon-Khaen, and 400 in Trang.

\section{Instruments}

Three self-administered scales were used in the study, measuring sociodemographic and socioeconomic factors, quality of life, and ADLs.

\section{Sociodemographic and socioeconomic status}

This scale measured sociodemographic variables that referred to region, age, gender and marital status, while the most common measures of socioeconomic status were household income and education. For instance, age was categorised into four groups, 6069 years, $70-79$ years, $80-89$ years, and 90 years and over. Income was divided into five categories based on median and standard deviation, including 500-999 Baht (\$ 17-34), 1000-4999 Baht (\$ 35-164), 5000-9999 Baht (\$165-334), 10,000-49,999 Baht (\$335$1664)$ and 50,000 Baht and over (>1665 \$).

\section{Quality of life}

The WHOQOL-OLD instrument was developed by the WHOQOL group to measure the quality of life of older adults. ${ }^{26}$ The scale contains 24 items divided into six facets, with each item measured on a 5-point Likert-type scale ranging from 1 (not at all) to 5 (an extreme amount). The first facet was sensory abilities (SA), where respondents rated their degree of sensory impairment, loss of sensory abilities, and problems with sensory function during the last two weeks. Autonomy (AUT) was the second facet, assessing freedom, control of individual future, being respected, and doing favourite activities. The past, present and future (PPF) facet evaluated satisfaction with opportunities in life, receiving recognition, achievements in life, and looking forward to a happy future. Social participation (SOP) included questions about satisfaction with how time was spent each day, having an appropriate activity level, participating in community activities, and having sufficient activities each day. The death and dying (DDA) facet evaluated individual attitudes toward concerns, worries, and fears about death and dying. The last facet contained intimacy (INT) questions related to feeling a sense of companionship, experiencing love, and having opportunities to love and be loved. The total score for each facet was calculated by summing the values of individual items. The internal consistency (Cronbach's alpha) of WHOQOL-OLD used in the study was 0.88 . The scores were dichotomised as a normal quality of life (equal to $75^{\text {th }}$ percentile), and a high quality of life (above $75^{\text {th }}$ percentile) for each facet.

\section{Activities of daily living}

The scale was derived from two classical instruments, the Lawton Scale ${ }^{27}$ and Barthel Index. ${ }^{28}$ The Lawton Scale asks respondents to evaluate eight daily tasks, including using the telephone, taking medication, handling finances, using transport, shopping, food preparation, laundry and housework, while the Barthel Index scale rates ten daily behaviours, including feeding, 
bathing, grooming, dressing, toilet use, mobility, stairs, transferring, and bowel and bladder control. Items related to handing finance and shopping were removed from the Lawton Scale and replaced with a 400 -metre walk and carrying $1 \mathrm{~kg}$ object to market (100 metres). Each item was measured on a 4-point scale, 0 (never done), 1 (cannot do), 2 (require assistance), and 3 (can do - independent). The Cronbach's alpha of the measurement was 0.85 . All items were summed and divided into dichotomous categories, dependent living (equal to $75^{\text {th }}$ percentile), and independent living (above $75^{\text {th }}$ percentile).

\section{Data analysis}

Socioeconomic status was analysed as numbers and percentages. Because the data were ordinal, the non-parametric MannWhitney $U$ test was used to identify differences based on socioeconomic status in the six facets of quality of life and in ADL. Binary logistic regression was used to identify the association between socioeconomic factors (incomes, education, and healthcare insurance card), daily activities and quality of life subdomains. Those indices were selected to be a socioeconomic status representative. Odd ratios (ORs) as crude and adjusted were operated to predicted probability of the association between factors with $95 \%$ confidential intervals. The indices, including age, sex, marital status, and regional areas were adjusted as covariates in the logistic regression model. $\mathrm{P}$ values of less than .05 were considered statistically significant. SPSS for Windows version 20.0 (IBM Corporation, Armonk, NY, USA) was used for data entry and analyses.

\section{Results}

The relations between sociodemographic, socioeconomic status and activities of daily living (ADL) are shown in Table 1 . The majority of respondents were female, aged 60-70 years, married, and had completed primary school. There were significant differences between all sociodemographic variables (region, gender, and marital status), socioeconomic status (education, income) and ADL. Gender was important, with $61 \%$ of dependent respondents being female whereas only $47 \%$ of those living independently were female. More male seniors seemed to live independently than their female counterparts. Likewise, younger seniors aged 60-69 were $77 \%$ more capable of performing daily routing activities than older persons. With socioeconomic factors, there were more respondents in the lowest income group (less than \$ 35 a month)

Table 1. Effects of sociodemographic and socioeconomic factors and activities of daily living ( $\mathrm{n}=1678)$.

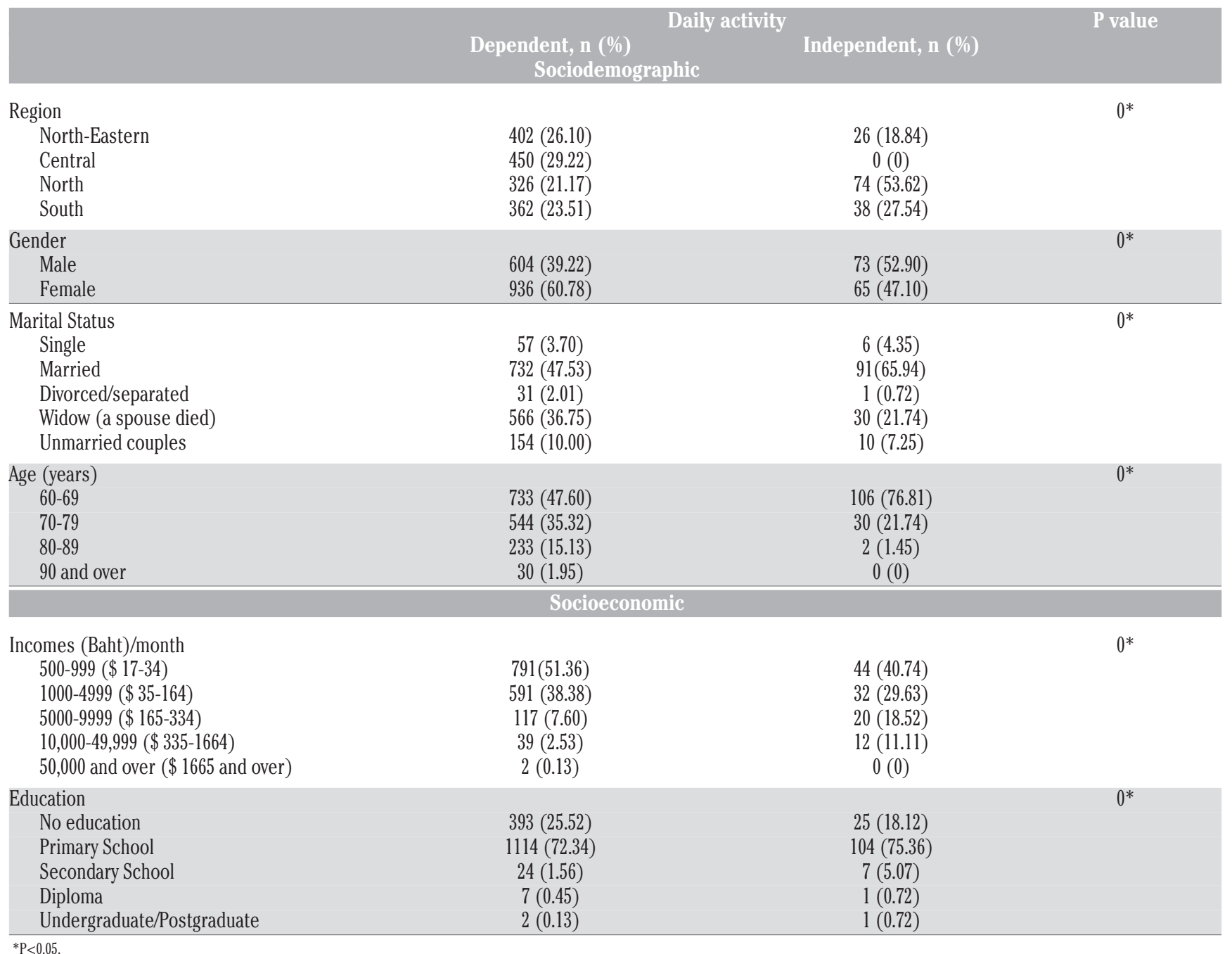
${ }^{*} \mathrm{P}<0.05$. 


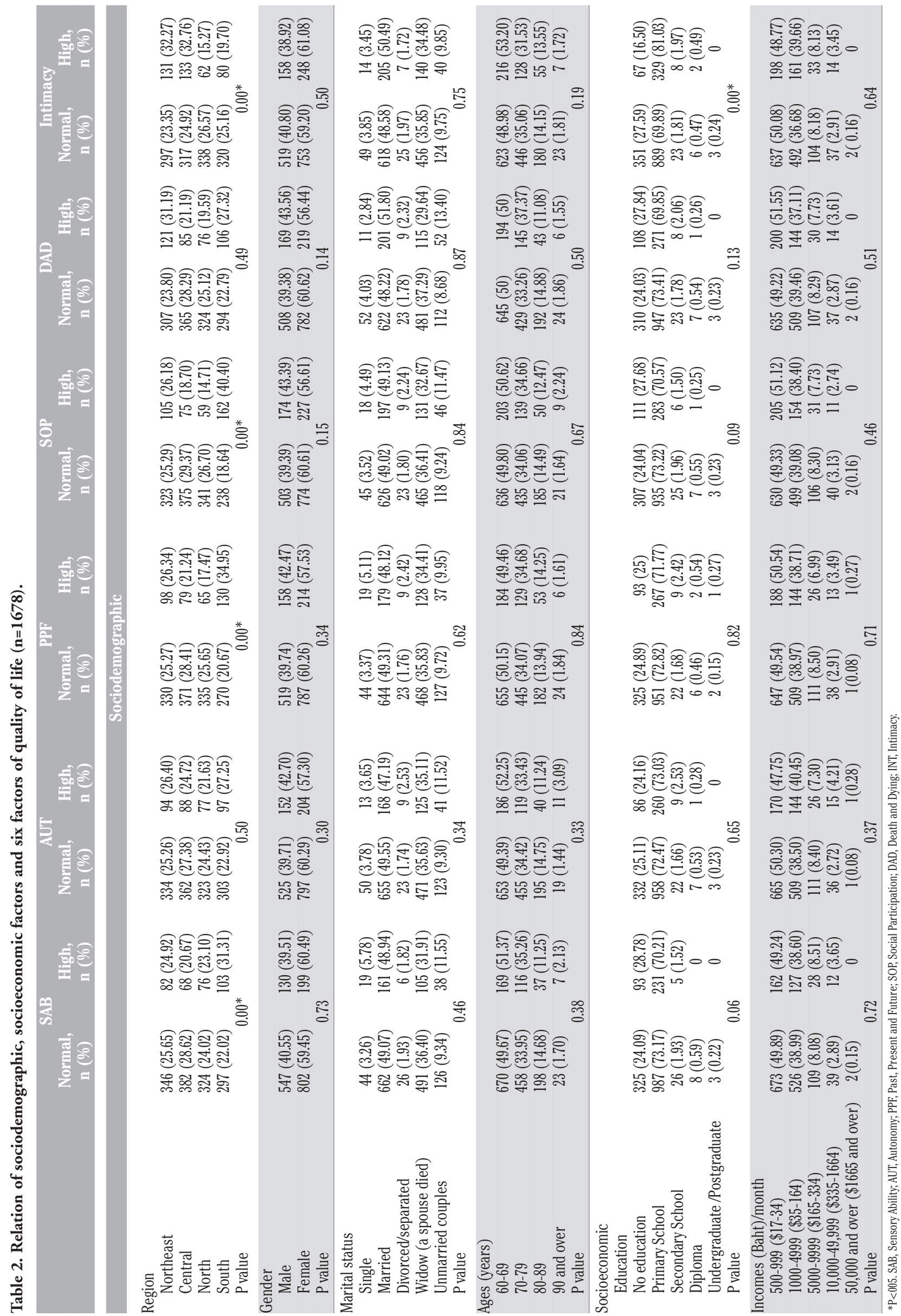


than in any other income bracket, comprising $52 \%$ of dependent and $41 \%$ of independent respondents. Findings indicated that seniors with low incomes (\$17-164) were more likely to be living independently than those with higher incomes. The majority of respondents (about 75\%) in both dependent and independent living categories had primary school education only.

The results in Table 2 show the relation of sociodemographic and socioeconomic factors to six aspects of quality of life. With sociodemographic variables, there were statistically significant differences based on region of residence for all facets of quality of life except autonomy and death and dying. For sensory ability, $31 \%$ of respondents scoring high lived in the South region. Likewise, $35 \%$ of those scoring high on past present and future, and $40 \%$ rated high on social participation came from the South region. People living in the South region had high levels of quality of life, with more having no sensory loss, being satisfied their past, present and future, and engaged in social activities. Of those rated high for intimacy, 33\% were from the Central region and $32 \%$ from the Northeast. There were no significant differences in quality of life scores for gender, marital status, and age. When considering socioeconomic aspects, education level had a significant effect on intimacy scores, particularly for older people with no formal education. These senior adults seemed more interested in engaging sexual intimacy than others with more education whereas income was not related to quality of life aspects.

The aim of the study was to assess the influence of socioeconomic aspects (income and education) on quality of life and daily activity, so sociodemographic variables (gender, marital status, regional areas and ages) were adjusted for data analysis (Table 3). When considering each category of quality of life, $40 \%$ of elders who had a low income were more likely to be concerned about past achievements, recognition in the present and the future, and they were less likely to accept death and dying, with 0.72 adjusted ORs (95\%CI: 0.53-0.98). Similarly, 32\% of seniors with low levels of education (primary school) were fearful of facing death in the final stage of life. However, elders with low and middle incomes were more engaged in social activities to improve their quality of lives, with 1.38 adjusted ORs (95\%CI: 1.01-1.90), and 2.05 (95\%CI: 1.22-3.43), respectively. Additionally, $93 \%$ of elders with low levels of education were more likely to be involved in intimate relationship. Elders who had a healthcare insurance card were less likely to be anxious about the past, present and future and seemed less likely to participate in social engagements, with 0.16 adjusted ORs (95\%CI: 0.03-0.94). Seniors living independently were significantly engaged in intimacy, with 1.57 adjusted ORs $(95 \% \mathrm{CI}$ : 1.02-2.41), but were not significantly associated with other categories of quality of life. All socioeconomic indices and daily activities did not seem to be associated with total quality of life (Table 3). In Table 4, the association of socioeconomic variables (income and education) with daily life activities are presented. There was no association between income and daily life activities whereas there was a strong relation between level of education and ADL. Overall, $85 \%$ of older persons with primary school education were more likely to live independently, with 1.85 adjusted ORs $(95 \% \mathrm{CI}$ : 1.12-3.07). Likewise, for seniors who had obtained a secondary school certificate, the level of living independently increased nearly fivefold compared with seniors with no education, with 4.58 crude ORs (95\% CI: 1.80-11.66) and 3.55 adjusted ORs (95\% CI: 1.23-10.21). While seniors with diploma and higher education displayed a strong functional mobility, the difference was not statistically significant, 1.79 adjusted ORs (95\%CI: 0.31-10.26).

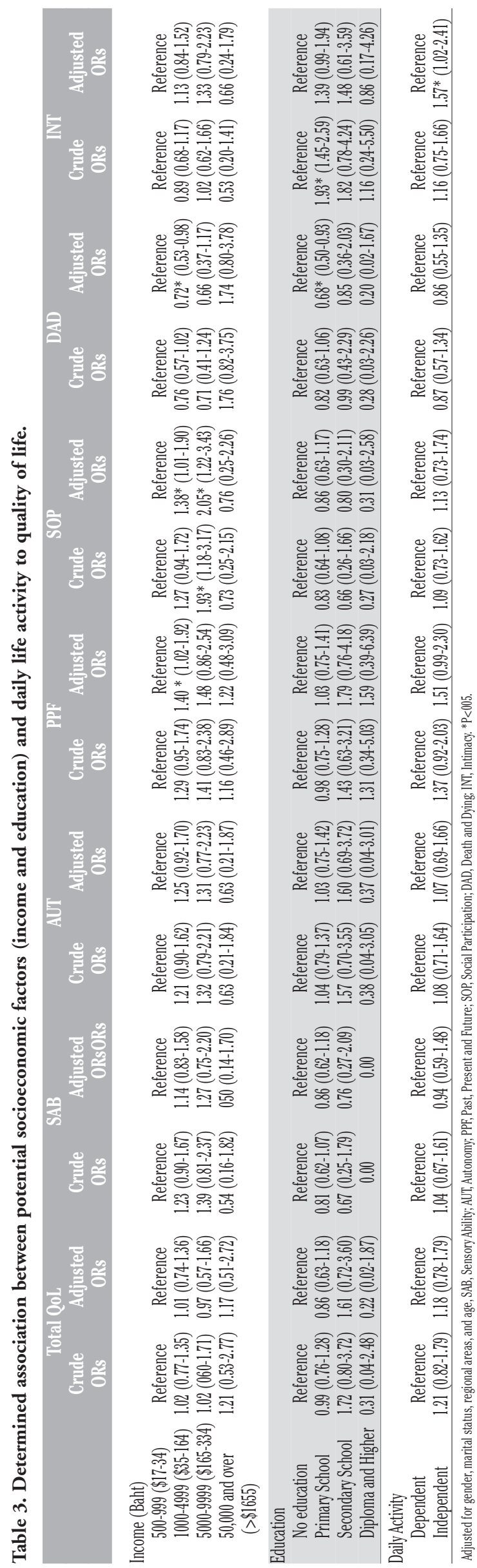




\section{Discussion}

The degree of complexity in performance of activities of daily living depends on task requirements. As people age, they are less likely to live independently because of reduced physical functioning. The findings have clearly indicated that female seniors and seniors with low incomes were less likely to live independently. Likewise, a prospective study carried out with eight years' followup in China found ADL disability rates gradually increased with older age, and disability rates in females $(7.7 \%)$ were higher than in male seniors $(6.5 \%)$. The average increase in the disability rate was $0.16 \%$ per year in younger frail adults compared with $0.48 \%$ a year in older frails. ${ }^{29}$ The WHO has pointed out the high prevalence of disabilities among women, people living in poverty, and seniors in developing countries. ${ }^{30}$ This is similar to an empirical study in the United States that found increasing age, female gender, and being married strongly predicted difficulties in daily life activities, such as taking medication, grocery shopping, preparing meals and using the telephone. ${ }^{31}$ A study in Nepal showed that gender was related to functional disability, travelling, and taking medicine. ${ }^{32}$ With regard to socioeconomic status (income and education), in the present study respondents with higher education levels were more likely to be living independently than respondents with no formal education. Consistently, Chinese elders with higher education levels performed ADL better than their less educated peers. ${ }^{24}$ In Korea, senior adults with a high level of education performed better on ADL than elders with no schooling (Park, Jang, \& Kim, 2010). A postulated explanation may be that education attainment is the most influential aspect of enhancing physical and mental functioning through engaging in better health behaviours and making better use of preventive and therapeutic health approaches which lead to healthy living or even delayed onset of health problems. ${ }^{33}$ High income did not appear to be a good predictor for physical impairment in this study. Senior adults with higher incomes may be more able to access expensive medications or private hospitals, but in this study income did not prevent the onset of chronic diseases or physical disabilities corresponding with ageing in the way that education did.

With regard to quality of life, the findings showed that region of residence influenced the quality of life of Thai seniors. Respondents living in the South region were more likely to rate highly on nearly all facets of quality of life. Southern Thailand has been an area of high economic growth and is a popular tourist destination, along with Bangkok, the capital city. A World Bank report in 2004 pointed out that there are 0.66 million people living below

Table 4. Determined associations between potential socioeconomic factors (income and education) and activities of daily living.

Crude ORs Daily life activity

Income (Baht)

500-999 (\$17-34)

1000-4999 (\$35-164)

5000-9999 (\$165-334)

50,000 and over $(>\$ 1655) \quad 1.57(0.46-5.38)$

Education

No education

Primary school

Secondary school

Diploma and higher

Reference

$1.48(0.95-2.30)$

$1.97(0.98-3.96)$

$1.57(0.46-5.38)$

Reference
$1.46(0.93-2.30)$
$4.58(1.80-11.66)^{*}$
$3.49(0.71-17.03)$

Adjusted for gender marital status, regional areas and age $* \mathrm{P}<0.05$ the poverty line in southern Thailand compared with 0.11 million in Bangkok. ${ }^{34}$ This could suggest that respondents in the South region have had healthier lives than those in other regions. According to quality of life facets, this study found that lowincome elders were very concerns about the past, present, and the future and were less likely to accept the death and dying circumstance in the later life. Similarly, elders with low-education attainment did not seem to embrace the death in late stage of life. As a result, senior adults with fewer economic resources were more likely to participate in social activities held by the communities and friends in order to distress about the future. Likewise, elderly Turkish living with poor financial situations was far more anxious about the past, present and future but was more likely to accept the death and dying rather than ignored or denied which was unlikely in Thai seniors. Turkish elders were enjoyable to spend times in social engagements, ${ }^{35}$ as similar as the findings of the study. An Iranian study by Tajvar and colleagues claimed that the financial resources were accounted for the most significant determinant of health-related quality of life compared to other all factors. ${ }^{36}$ An earning good income is an important asset for elders to get access not only basic needs of life but also luxury welfare they desire, including holidays, private hospitals and unexpected expenses in the future. Senior adults who lived with limited financial resources, are more likely to have high level of emotional stress in regard to uncertain future, so that engaging in social activities may be maintained their self-identities, keeping them active, ${ }^{37}$ maintain their connections with friends and exchange psychological and material supports for each other. ${ }^{38}$ Therefore, encouraging senior adults to engage in social activity in later life will be enhanced both psychological and physical wellbeing and may result in live longer and healthier.

\section{Conclusions}

In conclusion, level of education strongly influenced the activities of daily living of Thai persons aged 60 years and over, but independent/dependent living did not appear to affect quality of life. However, poor financial situations were strongly linked to quality of life in particular anxious of past present and future but were more likely to encourage elders to be involved in social activities in order to reduce the stress levels even they hardly accepted bereavement. Despite socioeconomic status, chronic illness and co-morbidities are the predominant risk factors toward quality of life in elders that should be paid more attention for the future study, and also the other factors should be included, such as social networks, psychological disorders (depression, anxiety), and life satisfaction.

\section{Limitation of the study}

This study has some limitations in relation to study design, which is a cross-sectional study. A cross-sectional study is able to show strength of relationships between socioeconomic factors and quality of life or daily life activities, but it is difficult to infer a causal relationship among factors and quality of life. The study design excluded seniors with cognitive impairments, which may limit the generalisability of the results. Several key issues have not been identified, especially chronic conditions and medications that may affect quality of life and disabilities in elders. 
Correspondence: Nualnong Wongtongkam, School of Biomedical Sciences, Charles Sturt University, 1448-Building, Panorama Avenue, Bathurst, New South Wales, 2795 Australia.

Tel.: +61.2.63384309 - Fax: +61.2.63384994.

E-mail: nwongtongkam@csu.edu.au

Key words: Elderly; Daily living; Quality of life; Socioeconomic; Thailand. Contributions: RS conducted a research design and data collection; SW, DH, KY carried out data collection. CR and NW assisted in editing manuscript and data analysis.

Conflict of interest: the authors declare no potential conflict of interest. Funding: the study was supported by the Higher Education Research Promotion and National Research University Project of Thailand, (WCU-58-039-AS), Office of the Higher Education Commission and Chulalongkorn University.

Received for publication: 8 March 2017.

Accepted for publication: 15 June 2017.

(C) Copyright R. Somrongthong et al., 2017

Licensee PAGEPress, Italy

Journal of Public Health Research 2017;6:862

doi:10.4081/jphr.2017.862

This work is licensed under a Creative Commons Attribution NonCommercial 4.0 License (CC BY-NC 4.0)

\section{References}

1. Breakwell C, Bajekal M. Health expectancies in the uk and its constituent countries, 2001. Health Stat Q 2006;18-25.

2. Karcharnubarn R, Rees P, Gould M. Healthy life expectancy changes in Thailand, 2002-2007. Health Place 2013;24:1-10.

3. Salomon JA, Wang H, Freeman MK, et al. Healthy life expectancy for 187 countries, 1990-2010: a systematic analysis for the global burden disease study 2010. Lancet 2012;380:2144-62.

4. United Nations. Population ageing and living arrangements of olders persons: critical issues and policy responses. Population Bulletin of the United Nations, Special Issue Nos. 42/43. Sales No. E.01.XIII.16.2001. Available from: http://www.un.org/esa/ population/publications/bulletin42_43/bulletin42_43.htm

5. United Nations. World population prospects: the 2008 revision. Available from: http://www.un.org/esa/population/publications/ wpp2008/wpp2008_highlights.pdf

6. Prasartkul P, Vapattanawong P. Thai health. Birth 2012:12-3.

7. Knodel J, Prachuabmoh V, Chayovan N. The changing well-being of thai elderly: an update from the 2011 survey of older persons in thailand. 2013.Available from: http://www.psc.isr.umich.edu/pubs/pdf/rr13-793.pdf

8. World Bank. Overview-Thailand. 2017. Available from http://www. worldbank.org/en/country/thailand/overview.

9. Carmichael GA. Exploring thailand's mortality transition with the aid of life tables. Asia Pacific Viewpoint 2011;52:85-105.

10. National Statistic Office. 2007 survey of the older persons in Thailand. 2007. Available from: http://web.nso.go.th/en/survey/keystat/keystat 08.pdf

11. Moody-Ayers S, Lindquist K, Sen S, Covinsky KE. Childhood social and economic well-being and health in older age. Am J Epidemiol 2007;166:1059-67.

12. Tucker-Seeley RD, Li Y, Sorensen G, Subramanian SV. Lifecourse socioeconomic circumstances and multimorbidity among older adults. BMC Public Health 2011;11:313.

13. Jagger C, Cox B, Roy SL, the EHEMU Team. Health expectancy calculation by the Sullivan method: a practical guide, 3rd ed. 2007.

14. Sun W, Aodeng S, Tanimoto Y, Watanabe M, Han J, Wang B, et al. Quality of life (qol) of the community-dwelling elderly and associated factors: A population-based study in urban areas of china. Arch Gerontol Geriatr 2015;60:311-6.

15. House JS, Lepkowski JM, Kinney AM, et al. The social stratification of aging and health. J Health Soc Behav 1994;35:213-34.

16. Herd P, Goesling B, House JS. Socioeconomic position and health: The differential effects of education versus income on the onset versus progression of health problems. J Health Soc Behav 2007;48:223-38.

17. Zimmer Z, Amornsirisomboon P. Socioeconomic status and health among older adults in thailand: An examination using multiple indicators. Soc Sci Med 2001;52:1297-11.

18. Zimmer Z, Prachuabmoh V. Comparing the socioeconomic statushealth gradient among adults 50 and older across rural and urban areas of thailand in 1994 and 2007. Soc Sci Med 2012;74:1921-8.

19. Rukumnuaykit P, Pholphirul P. Happiness from social capital: An investigation from micro data in rural thailand. Commun Dev 2016;47:56273.

20. Veehoven R. Quality-of-life and happiness: not quite the same. Fac Soc Sci 2001;18:67-95.

21. Cambois E, Clavel A, Romieu I, Robine JM. Trends in disability-free life expectancy at age 65 in france: Consistent and diverging patterns according to the underlying disability measure. Eur $\mathrm{J}$ Ageing 2008;5:287-98.

22. Zhang M, Zhu Z, Chen P. Community investigations of the adl and medical conditions of the elderly in shanghai. Zhonghua Yi Xue ZAZhi 1998;78:124-7.

23. Xu J, Qiu J, Chen J, et al. Lifestyle and health-related quality of life: A cross-sectional study among civil servants in china. BMC Public Health 2012;12:330.

24. Ji J. Disparities of the chinese elderly: activities of daily living and socioeconomic characteristics. Act Adapt Aging 2013;37:19-46.

25. Ministry of Social Development and Human Security (MSDHS). Annual report on ageing (Thai version). 2013

26. Power M, Quinn K, Schmidt S. Development of the whoqol-old module. Qual Life Res 2005;14:2197-214.

27. Lawton MP, Brody EM. Assessment of older people: self-maintaining and instrumental activities of daily living. Gerontologist 1969;9:179-86.

28. Mahoney FI, Barthel DW. Functional evaluation: the barthel index. Maryland State Med J 1965;14:61-5.

29. Jiang J, Tang Z, Meng XJ, Futatsuka M. Demographic determinants for change in activities of daily living: a cohort study of the elderly people in beijing. J Epidemiol 2002;12:280-6.

30. World Health Organization. World bank (2011); world report on disability. Malta: WHO; 2012.

31. Reynolds SL, Silverstein M. Observing the onset of disability in older adults. Soc Sci Med 2003;57:1875-89.

32. Chalise HN, Saito T, Kai I. Functional disability in activities of daily living and instrumental activities of daily living among nepalese newar elderly. Public Health 2008;122:394-6.

33. Ross C, Mirowsky J. Education, social status, and health. New York: De Gruyter; 2003.

34. World Bank. Thailand economic monitor. <november 2005. Available from: http://www.worldbank.org/en/country/thailand/publication/thailand-economic-monitor-reports

35. Unalan D, Gocer S, Basturk M, et al. Coincidence of low social support and high depressive score on quality of life in elderly. Eur Geriatr Med 2015;6:319-24.

36. Tajvar M,Arab M, Montazeri A. Determinants of health-related quality of life in elderly in Tehran, Iran. BMC Public Health 2008;8:323.

37. Arber S, Perren K, Davidson K. Involvement in social organizations in later life: Variation by gender and class. In: Andersson L, ed. Culture gerontology. Westport: Auburn House; 2002. pp.77-93.

38. Herzog AR, Ofstedal MB, Wheeler LM. Social engagement and its relationship to health. Clin Geriatr Med 2002;18:593-609. 